\title{
Finding legitimacy for the role of budget impact in drug reimbursement decisions
}

\author{
Maartje G. H. Niezen, Antoinette de Bont \\ Erasmus MC \\ Jan J. V. Busschbach \\ Erasmus $M C$ and De Viersprong \\ Joshua P. Cohen \\ Tufts University
}

Elly A. Stolk

Erasmus MC

Objectives: Research has shown that effectiveness, cost-effectiveness, and severity of illness each play a role in drug reimbursement decisions. However, the role of budget impact in such decisions is less obvious. Policy makers almost always demand a budget impact estimate yet seem reluctant to formally include budget impact as a rationing criterion. Health economists even reject budget impact as a legitimate criterion. For these reasons, it is important to examine its use in rationing decisions, and rationales underlying its use.

Methods: We trace several rationales supporting the use of budget impact through a literature review, supplemented by semistructured interviews with eleven key stakeholders involved in drug reimbursement decisions in the Netherlands.

Results: Budget impact arguments are used in certain instances, although policy makers appear uncomfortable with its use because well described rationales still are lacking. In addition, we identify the following rationales to support budget impact as a rationing criterion: opportunity costs, loss aversion, uncertainty and equal opportunity.

Conclusions: Budget impact plays a role in drug reimbursement decisions and has rationales to support its use. However, policy makers do not easily admit that they consider budget impact and are even reluctant to explicitly use budget impact as a formal criterion. A debate would strengthen the theoretical foundation of budget impact as a legitimate criterion in the context of drug reimbursement decisions. Such discussion of budget impact's role will also enhance policy-makers' accountability.

Keywords: Pharmaceutical policy, Healthcare rationing, Budget impact, The Netherlands

It is acknowledged that effectiveness, cost-effectiveness, and severity of illness play or should play a role in drug reimbursement decisions $(9 ; 13 ; 39 ; 43)$. Less consensus can be

We acknowledge financial support from The Netherlands Organisation for Scientific Research (NWO) under the Ethics Research and Government program (project 253-20-022). We thank all participating health professionals and policy makers for their collaboration. found for the role of budget impact as an additional decision criterion. Especially health economists argue that the budget impact argument undermines cost-effective allocations, and therefore leads to suboptimal distributions of health in the populations $(32 ; 40 ; 42)$. Nevertheless, given increasingly stringent budget constraints, policy makers have a need to know what the impact of any new technology will be on 
their limited budget. Budget impact analyses provide such information $(25 ; 27 ; 30)$. Budget impact refers to "the total costs that drug reimbursement and use entail with respect to one part of the health care system, pharmaceutical care, or the entire health care system, taking into account the possible reallocation of resources across budgets or sectors of the health care system" (10). If on the basis of cost-effectiveness information a positive reimbursement decision is suggested, budget impact addresses the question of what amount of resources would be needed to implement the decision. For reimbursement purposes, several national health technology assessment agencies, including the Healthcare Insurance Board in the Netherlands (CVZ) and the Pharmaceutical Benefits Advisory Committee (PBAC) in Australia, already require that drug manufacturers submit both cost-effectiveness and budget impact analyses of newly approved pharmaceuticals (27).

Advocates of the budget impact criterion point out that cost-effectiveness analyses fail to meet the needs of policy makers, whose overriding concern is not so much the costeffectiveness of the interventions, but their budget constrains (40). Cost-effectiveness analysis does not address affordability. This is especially a problem when resource requirements for the funding of new technologies are relatively large. The precise role of budget impact and its rationale in drug reimbursement decisions have not been made clear in the literature. Whereas a small number of studies have addressed descriptions of methods for conducting budget impact analysis $(25 ; 26 ; 34 ; 40)$, the literature on drug reimbursement decisions is still dominated by formal cost-effectiveness and severity of illness-analyses. This may be due to the fact that budget impact is not perceived as a legitimate decision criterion as it lacks scientific rigor; meaning rational use of evidence based, and explicit knowledge (4). In this study, we outline current policy practices in which budget impact plays a role in drug reimbursement decisions. Next, we provide a synopsis of results gathered from interviews with eleven key stakeholders involved in drug reimbursement decisions in the Netherlands. Subsequently, we examine possible rationales underlying the use of budget impact as a decision criterion for resource allocation. In so doing, we hope to provide more explicit knowledge for the use of the budget impact as an argument for allocation in health care.

\section{METHOD}

Our initial examination of the role of budget impact as a decision criterion consisted of a literature search in PubMed covering the period 1990-2007. Instead of using Mesh or Emtree terms, we used more specific (combinations of) keywords; "budget(ary) impact," "affordability," "drug reimbursement and budget impact /affordability," and "drug reimbursement and rationing / prioritization." In addition, we used a snowball method to generate references starting with the milestone articles by Trueman et al. (40) and Mauskopf (25). We sup-
Table 1. Background of Interview Respondents

\begin{tabular}{|c|c|c|}
\hline Organization & Employment & $n$ \\
\hline Ministry of Health & $\begin{array}{l}\text { Policy associate drugs and } \\
\text { medical technology }\end{array}$ & 2 \\
\hline \multirow[t]{2}{*}{$\begin{array}{l}\text { Healthcare insurance board } \\
\quad \text { (CVZ) }\end{array}$} & $\begin{array}{l}\text { Policy associate benefit } \\
\text { package decisions }\end{array}$ & 2 \\
\hline & $\mathrm{CEO}$ & 1 \\
\hline $\begin{array}{l}\text { Dutch organization for } \\
\text { innovative drugs (Nefarma) }\end{array}$ & $\begin{array}{l}\text { Policy associate drug } \\
\text { reimbursement }\end{array}$ & 2 \\
\hline $\begin{array}{l}\text { UMC St Radboud, } \\
\text { Department of } \\
\text { Epidemiology, Biostatistics } \\
\text { and Health technology } \\
\text { assessment }\end{array}$ & $\begin{array}{l}\text { Health economist / } \\
\text { scientific researcher }\end{array}$ & 1 \\
\hline Canisius-Wilhelmina Hospital & CEO & 1 \\
\hline $\begin{array}{l}\text { The NVZ Dutch Hospitals } \\
\text { Association }\end{array}$ & Policy advisor health care & 1 \\
\hline $\begin{array}{l}\text { Erasmus MC, Institute of } \\
\text { Health Policy and } \\
\text { Management }\end{array}$ & $\begin{array}{l}\text { Professor in "Societal } \\
\text { aspects of hospital drug } \\
\text { policy" and also a hospital } \\
\text { pharmacist }\end{array}$ & 1 \\
\hline
\end{tabular}

${ }^{a}$ An umbrella organization for the Dutch innovative pharmaceutical industry.

Table 2. Topic List Semistructured Interviews

- How do you define budget impact?

- What is the relevance of budget impact as a criterion in drug reimbursement decision making?

- When is budget impact used as a decision criterion?

- In what decision process (e.g., budget re-allocation, admission to the benefit package, etc.)?

- When is budget impact used in the drug reimbursement decision-making process?

- Is budget impact's use formally acknowledged? (Are there official reports on budget impact similar to cost-effectiveness and severity of illness?)

- Is budget impact mere addition to cost-effectiveness information or can it trump cost-effectiveness and severity of illness arguments too?

- Can you name specific drug types (e.g., orphan drugs, drugs for lifestyle conditions) for which budget impact is most likely to play a role?

- Do you know of specific cases in which budget impact played an important role?

- What motives or argumentations are there to use budget impact as a decision criterion in resource allocation?

- Have you used budget impact analyses to guide your decisions?

- If yes, what was your motivation to do so?

plemented the literature review by conducting semistructured interviews with eleven key stakeholders involved in drug reimbursement decisions in the Netherlands (see Tables 1 and 2 ). The interviewees were selected on the basis of their involvement in reimbursement decisions of pharmaceuticals in which budget impact had been a major discussion point. The interviews were recorded and converted to transcripts, which have been hand coded to analyze the content of the 
interviews. The codes were discussed among the researchers (code words were, e.g., budget impact/costs, costeffectiveness, objective/scientific rationing, uncertainty, opportunity costs, and equality) (19).

\section{Current Practice}

Use of budget impact is very much a reality in current healthcare decision making; policy makers use budget impact as a decision criterion in certain instances. Results from a multinomial modeling of NICE decision making, for example, showed that interventions with a high budget impact were more likely to be recommended for conditional reimbursement and use, that is, with restrictions, holding clinical- and cost-effectiveness, as well as other considerations constant. The model showed that " $\mathrm{t}]$ he potential budget impact $[. .$. was significantly higher for those interventions that were recommended for restricted use than those recommended for routine use," without restrictions (12).

In the Netherlands, it appears budget impact also played a significant role in a number of drug reimbursement decisions (31). An example is the reimbursement decision for clopidogrel, trastuzumab, and the entire class of statins. In 1999, CVZ advised the Ministry of Health to admit clopidogrel for all approved indications to the health benefit package on the grounds of its favorable clinical- and cost-effectiveness profiles. However, because of its relatively high cost compared with existing therapy (acetylsalicylic acid) combined with the potential for substantial off-label use, CVZ recommended severe restrictions on clopidogrel's use. Despite CVZ's recommendations, the Ministry of Health decided not to reimburse clopidogrel at all, citing budget limitations $(15 ; 32 ; 42)$. Subsequent to the Ministry's decision, a successful legal challenge by the drug manufacture obliged the Ministry to reimburse clopidogrel for all approved indications. Nevertheless, the Ministry has not reimbursed new indications for clopidogrel, and continues to place severe restrictions on its reimbursement and use, appealing again to high budget impact due to the potential for substantial offlabel use in a large patient population $(2 ; 15)$. The Ministry expressed similar concerns about reimbursement of statins (31). The large pool of potential users of statins suggests that a positive reimbursement decision would exert significant upward pressure on pharmacy expenditures. This reasoning led to the Ministry's decision to place conditions on the reimbursement of statins (23).

Although reimbursement of statins for specific subpopulations may be explained by stratified cost-effectiveness analyses (across sub-populations), Niezen et al. (31) show that strictly prescribing in accordance with the conditions of reimbursement imposed on statins entails under-treatment, according to the (evidence based) professional guidelines. This example demonstrates that budget impact likely played a role. A third example, the in-patient cancer drug trastuzumab (breast cancer), is generally seen as cost-effective. The drug's budget impact is high, owing to its relative high price per patient and the relatively high volume of breast cancer patients who would be considered eligible for its use. Recent research demonstrates that trastuzumab was unevenly distributed among patients in The Netherlands (7). Although hospitals received additional funding for trastuzumab, the cost of the drug grew much faster than the assigned budget, causing great pressure on the hospital pharmaceutical budget (33). Evidently, unequal access was caused in part by the "intolerably" high impact unrestricted reimbursement has on the local budget of certain hospitals.

\section{Interviews}

Most interviewed policy makers confirmed that budget impact did play a role in certain specific cases, such as clopidogrel and sildenafil. Budget impact becomes a more important factor when the uncertainty regarding other criteria, such as cost-effectiveness and severity of illness is high. However, the interviewed policy makers could not explain how the budget impact criterion precisely interacts with effectiveness, cost-effectiveness, and severity of illness. The respondents confirmed that budget impact played a role, but that its role was intuitive or based on a "gut feeling" (Respondent VIII, 2006). The most common reply was that "it depends on the other case specific factors." Moreover, policy makers did not provide a concrete definition of what is meant by budget impact and what budget impact analyses specifically assess.

I do not know the term budget impact very well, thus my understanding of it would depend on the context in which I encountered it, and not as part of my understanding of health economics. (Respondent $\mathrm{X}, 2006)$

The lack of clarity surrounding budget impact does not appear to hamper its use.

The higher the budget impact, the more therapeutic value there must be and efficiency determines the outcome, just because the effect on the budget is bigger. As uncertainty [regarding an intervention's effectiveness] increases, one could choose to be more reserved in deciding to fund. Nevertheless, patients' interests and therapeutic value are the focus of interest, also for the Minister [of Health]. Only, the Minister is also responsible for not exceeding growth targets and thus will be more critical. (Respondent IX, 2006)

Policy makers have little incentive for formally discussing their concerns regarding the impact of reimbursement decisions on the (pharmacy) budget. Because reasonable arguments supporting the use of budget impact are lacking or not (yet) formulated, policy makers typically concentrate on using arguments of effectiveness, cost-effectiveness and severity of illness. Thus, policy makers rely on and interpret the available scientific, technical, and clinical data contained in evidence-based "cost-effectiveness analyses" or "health technology assessments." Such analyses offer them the supposed promise of a rational grasp of, and concomitant "control" 
over, healthcare decision making $(4 ; 5)$. Consequently, policy makers often rely only on information gathered from costeffectiveness analyses to justify their decisions, instead of explaining how budget impact had an effect on the decision.

Because we really think it is important to maintain efficacy and therapeutic value, because yes... that forms the core of the decisions that we make. So that cost or what you call budget impact, that is at the bottom of the list. (Respondent VIII, 2006)

Actually, we do not like the cost discussion. Because, indeed, in the case of clopidogrel, yes, we are not going to formally acknowledge it [cost or budget impact led to the decision]. And in the case of sildenafil, well, it felt more normal; you could explain more easily that we do not pay for erection disorders and that type of stuff. Yet, clopidogrel is sometimes a life-saving medication, although it is only so for one in a hundred users. But you do not want to go into a cost discussion. (Respondent VIII, 2006)

The citations above show how uncomfortable policy makers are with formally acknowledging that budget impact plays a role in reimbursement decisions. Implicitly, budget impact already seems to have a place in priority setting, although explicitly budget impact seldom is used as an argument for denying a drug reimbursement outright or imposing conditions on its reimbursement, given that it appears to lack scientific rigor or a rationale.

\section{Rationales in Favor of the Budget Impact Criterion}

Although the respondents did not give explicit rationales for budget impact, literature does show some rationales that justify budget impact's use as a rationing criterion. These rationales comprise the opportunity costs of reimbursement decisions, the fact each decision involves gains and losses that are evaluated differently, uncertainty and equal opportunity.

Opportunity Costs. One of the main arguments found in the literature in favor of using budget impact analyses, is a deficiency in common cost-effectiveness analyses; opportunity costs are disregarded $(6 ; 10 ; 18 ; 22 ; 35 ; 36 ; 38)$. Expansion of the benefit package will typically be considered when a drug has a favorable incremental cost-effectiveness ratio (ICER), suggesting that incremental health gains are worth the incremental costs. Most recently developed drugs, though, have positive cost-effectiveness ratios. Consequently, a positive reimbursement decision for a new intervention suggests the need to expand the budget for health care or some of the existing benefits in the benefit package would have to be eliminated to fund the new intervention. Whichever solution one chooses, there is an opportunity cost involved that must be considered. The opportunity cost of a positive reimbursement decision increases with the size of a drug's budget impact. One will have to sacrifice increasing amounts-less to spend on other public programs, or exist- ing health benefits-to fund the new drug. The higher the opportunity cost, the more one has to sacrifice, the less likely it will be for a drug to be reimbursed.

Moreover, the opportunity cost argument necessitates a re-evaluation of the justification of the value of the incremental ICER thresholds and their use in decision making $(17 ; 36 ; 38)$. Healthcare payers operating within a constrained budget may deny reimbursement of new medical technologies with a high budget impact because funding these interventions would lower the lambda $(\lambda)$, or threshold ICER, which is equal to the ICER of the last program selected for reimbursement before the budget is exhausted. In other words, $\lambda$ reflects the opportunity cost of marginal healthcare resources, or benefits foregone of the last unit of healthcare resources spent $(6 ; 17 ; 18 ; 35)$. A lower $\lambda$ could mean that other pharmaceuticals already in the benefits package would no longer meet the threshold. However, because not all cost-effectiveness ratios of treatments included in the current benefit package are known, neither is $\lambda$ known. Accordingly, Gafni and Birch (17) suggest that policy makers require actual information on the opportunity costs of marginal resources. A possible approach to priority setting combining information on (opportunity) costs, cost-effectiveness and health related benefits of drugs is program budgeting and marginal analysis (PBMA). "PBMA addresses allocative efficiency by providing a systematic framework for maximizing health related benefits for a given budget considering both the outcomes from, and costs of providing, a range of services" (16).

Loss Aversion; Endowment Effects. Policy makers may be more reluctant to exclude drugs from the collectively funded benefits package than to include them. A shared feeling among policy makers we interviewed is that taking something away from patients that works and with which they are already familiar outweighs the benefit of adding something new. This rationale is closely tied to opportunity costs. However in this case, it directly concerns what happens when a treatment is eliminated from the benefit package. It reflects the people's tendency to prefer avoiding losses to acquiring gains. Budget impact makes it possible to consider the actual felt loss, the endowment effect, in rationing decisions. The higher the budget impact, the more one has to sacrifice, the more loss is felt by health insurance payers and patients and less likely the decision is accepted. To illustrate, a person who loses $\$ 100$ will lose more satisfaction than another person will gain satisfaction from a $\$ 100$ windfall. In turn, there is a discrepancy between an individual's maximum willingness to pay for a good and the minimum compensation demanded to give up the good. There are several explanations for this phenomenon, described by Dupont and Lee (14) including the "endowment effect" which captures the overvaluation of a good that is in already in one's possession; the "status quo bias" which describes the preference to remain in a current state; and "prospect theory" 
where losses impact the agent's utility more than gains of the same magnitude $(14 ; 24)$. The inherent difficulty of having to exclude treatments from the current benefit package is enhanced by the fact that policy makers also have to choose which interventions to eliminate, while they have no list interventions with a ranked unfavorable (cost-) effectiveness. Consequently they have to justify their choices to society and may fear the public backlash that may ensue as happened in The Netherlands concerning the IVF reimbursement policy (29). An additional complication is that society interpreted the social health insurance package as a "social contract" which can not just be broken from one side (3).

Uncertainty. A third rationale for considering budget impact in resource allocation decisions is uncertainty. Invariably, there is uncertainty about the actual cost-effectiveness of new health interventions (21). Likewise, in healthcare finance, the budget implications of expansion of the benefit package are usually uncertain due to the fact that at the time of launch little is known about the extent to which a drug will be used (31). It is simply hard to estimate the size of the user population: will a newly approved drug only be used by those who suffer severely from a particular condition, or will it be used as well by those who have a milder form of the condition. Similarly, a newly launched drug may experience a broadening of indications through off-label use, further increasing uncertainty (1). Programs may therefore require more resources than initially budgeted.

In case reimbursement results in budget overspend, or when large deficits loom, uncertainty is a particularly acute problem. Uncertainty may explain why small-scale programs are often favored over large-scale programs (21). Policy makers have to adhere to strict budgets and therefore must consider opportunity cost. Typically, the potential for large deficits increases with the size of the patient population. Hence, policy makers prefer to diversify their "investments," which leads to an improved handling of uncertainty regarding unexpected costs, and a concomitant reduction in the risk of overspending (37). Thus, a large budget relates to more uncertainty and an increased need in a more precise budget impact analyses.

Equal Opportunity. Budget impact may also play a role in reimbursement decisions as a way to preserve equal opportunity. Policy makers appear to allocate resources to all those who suffer from a disease, irrespectively of the (cost-) effectiveness of treatment. This reflects a viewpoint of justice, that is, that people favor an equal distribution of health resources regardless of each person's potential to benefit from those resources. This concern with equality works two ways: it explains the tendency to reimburse ineffective treatments for rare diseases or small groups, and also the tendency not to reimburse certain treatments with high budget impact (41). For example, there are orphan drugs with unfavorable cost per QALY ratios, which are funded nevertheless, for example, imiglucerase and laronidase (28). Positive decisions to fund orphans appeal to the fact that the number of patients taking each orphan drug is very small, therefore the budget impact is limited (10). When all orphan diseases are taken together, however, it is estimated that 1 in 12 people in Europe have a rare disease. This is a fairly large group to make exceptions for (11).

There are also instances in which costly, yet costeffective medical interventions would consume more resources than available, if given to all eligible patients. Consequently subsidized access to the intervention cannot be guaranteed to all patients. In such circumstances, "people [appear to] place greater importance on equity than is reflected by cost-effectiveness analysis" (40) and would therefore rather choose a less cost-effective intervention available to all, than a very cost-effective intervention for some. Budget impact analysis can then be used to assess whether it is affordable to offer the cost-effective intervention to the entire patient population so that equal opportunity can be guaranteed, or whether instead a less cost-effective intervention can be offered to the entire population. Similarly, the rationale of equal opportunity explains why policy makers might prefer to preserve resources rather than spending most of it in one go.

\section{Policy Implications}

Budget impact, we demonstrate in this article, plays a role in drug reimbursement decisions. Dutch policy makers, we demonstrated, do not easily admit that they consider budget impact. In fact, policy makers are reluctant to explicitly use budget impact as a formal criterion. This study is relevant for policy makers who, to remain accountable by the public at large, are confronted with a transparency requirement.

This study identified four rationales for considering the budget impact of new drugs when a decision needs to be made about reimbursement. The first rationale is opportunity costs: A positive reimbursement decision for a new intervention suggests the need to expand the budget for health care, or to eliminate existing benefits to fund the new intervention. Whichever solution one chooses, there is an opportunity cost involved that must be considered. The second rationale relates to loss aversion: people may be generally unwilling to eliminate funding for existing benefits in favor of a new intervention. Budget impact considers the felt loss by assessing the amount of resources needed to make free. Third, budget impact is considered in relation to decision uncertainty. Fourth, people seem to favor an equal distribution of health resources regardless of each person's potential to benefit from those resources, reflecting equal opportunity concerns. These four theoretical rationales indicate budget impact's relevance in reimbursement decisions.

Economic consequences of positive reimbursement decisions, we claim, are not sufficiently explored when only cost-effectiveness of a new product is considered and not its budget impact. Therefore the question is how to integrate 
budget impact into a framework for reimbursement decisions that is based on cost-effectiveness. Due to inflexible budgets, risk of overspending, and political pressures, the application of cost-effectiveness is not as simple and straightforward as it is often advocated. For example, budget impact can trump the cost-effectiveness argument. An unfavorable ICER for a pharmaceutical treatment is less relevant to the policy maker when the total budget impact is low. Conversely, an adequate ICER can be trumped when the budget impact is high. However, what levels of budget impact and cost-effectiveness warrant such tradeoffs? We need to identify conditions under which a decision maker can comfortably withhold or initiate treatment, assured of a tolerable balance between the conflicting concerns. If guidance is lacking, the cost-effectiveness criterion cannot be put to its full potential, consistency of decision making is at risk, and decision makers will be vulnerable and exposed. Therefore, we need an open discussion to define what is acceptable or unacceptable. Such a discussion should also shed light on the motives for considering budget impact, because we need to acknowledge the fact that budget impact and cost-effectiveness analyses can be assessments based on different distributional and egalitarian rationales, namely equal opportunity and maximizing health. If budget impact is considered mainly because of the equal opportunity rationale, it is considered fair to ensure treatment for all patient groups, irrespective of the total health outcomes achieved. In other words, this particular rationale for budget impact calls into question if it is fair to allocate resources on basis of a utilitarian principle; the equal opportunity rationale reflects that people may also strive for resource allocation fairness by some form of procedural justice that ensures availability of treatment for all. Implications for the decisionmaking framework will then go beyond the need to facilitate application of cost-effectiveness, and require rethinking of the basis for resource allocation decisions.

Policy makers walk a fine line between increased transparency and increased efficiency; between specifying which criteria are used and how they should be used in explicit, evidence-based assessments, and providing information within a reasonable time-frame taking into account an implicit "societal correction" on the technical assessments to guarantee decisions are fair (8). Inevitably, certain decision factors remain implicit, partly because policy makers lack the time to reflect thoroughly on the decisions that they believe are sound; and also because they do not want to expose themselves to criticism from the public at large. Nevertheless, as we and others have shown, when put to the test of accountability, policy makers fail on account of their inadequate attempts to explain certain key policy decisions (20). In this study, we have demonstrated that budget impact can and should be openly discussed as a legitimate criterion in the context of drug reimbursement decisions. Open discussion of budget impact's role will enhance policy makers' accountability.

\section{CONTACT INFORMATION}

Maartje G. H. Niezen, MA (m.g.h.niezen@erasmusmc.nl), Junior Research Fellow, Institute of Health Policy Management, Antoinette de Bont, PhD (debont@bmg.eur.nl), Associate Professor, Health Care Management and Policy, Institute for Health Policy and Management, Institute for Technology Assessment, Erasmus MC, P.O. Box 1738, 3000 DR Rotterdam, The Netherlands, Jan J. V. Busschbach, PhD (j.vanbusschbach@erasmusmc.nl) Professor, Medical Psychology and Psychotherapy, Erasmus MC, P.O. Box 2040, 3000 CA Rotterdam, The Netherlands; Managing Director, Viersprong Institute for Studies on Personality Disorders (VISPD), De Viersprong, P.O. Box 7, 4660 AA Halsteren, The Netherlands

Joshua P. Cohen, PhD (joshua.cohen@tufts.edu), Senior Research Fellow, School of Medicine, Tufts University, 75 Kneeland Street, Boston, Massachusetts 02111

Elly A.Stolk, PhD (e.a.stolk@ erasmusmc.nl), Assistant Professor, Institute for Health Policy and Management/Institute for Technology Assessment, Erasmus MC Rotterdam, P.O. Box 1738, 3000 DR Rotterdam, The Netherlands

\section{REFERENCES}

1. Al MJ, Feenstra TL, Hout BA. Optimal allocation of resources over health care programmes: Dealing with decreasing marginal utility and uncertainty. Health Econ. 2005;14:655-667.

2. Amerongen L. Crisis on clopidogrel. [in Dutch: Crisis over clopidogrel] Med Contact (Bussum). 2003:58.

3. Anand P. QALYs and the integration of claims in health-care rationing. Health Care Anal. 1999;7:239-253.

4. Bal R, Van de Lindeloof A. Public participation in benefit package decisions. Learning from experiences abroad. [in Dutch: Publieksparticipatie bij pakketbeslissingen. Leren van buitenlandse ervaringen]. Rotterdam: Instituut Beleid en Management Gezondheidszorg; 2005.

5. Berg M, Van Der Grinten T, Klazinga N. Technology assessment, priority setting and appropriate care in Dutch health care. Int J Technol Assess Health Care. 2004;20:35-43.

6. Birch S, Gafni A. Information created to evade reality (ICER): Things we should not look to for answers. Pharmacoeconomics. 2006;24:1121-1131.

7. Borstkankervereniging Nederland. Report undertreatment of breast cancer patients with metastatic HER2-positive tumours [in Dutch: Rapport onderbehandeling van borstkankerpatienten met uitgezaaide HER2-positieve tumoren]. Utrecht: Borstkankervereniging Nederland; 2005.

8. Braat D, Van Rijen O, Ottes L. Sensible and durable care. [in Dutch: Zinnige en duurzame zorg]. Nieuwsbrief Ned Vereniging Bio-ethiek. 2007:14;3-5.

9. Briggs A, Gray A. Using cost-effectiveness information. BMJ. 2000;320:246.

10. Cohen J, Stolk EA, Niezen MGH. The increasingly complex fourth hurdle for pharmaceuticals. Pharmacoeconomics. 2007; $25: 727-734$ 
11. Cohen JP, Stolk EA, Niezen MGH. Role of budget impact in drug reimbursement decisions. J Health Polit Policy Law. 2008;33:225-247.

12. Dakin HA, Devlin NJ, Odeyemi IA. "Yes", "No" or "Yes, but"? Multinomial modelling of NICE decision-making. Health Policy. 2006;77:352-367.

13. Drummond M, Jonsson B, Rutten F. The role of economic evaluation in the pricing and reimbursement of medicines. Health Policy. 1997;40:199-215.

14. Dupont D, Lee SL. The endowment effect, status quo bias and loss aversion: Rational alternative explanation. J Risk Uncertain. 2002;25:87-101.

15. Eijgelshoven M, Wieringa N, Van Der Vaart R, et al. Clopidogel: Evaluation of its use and the additional conditions. [in Dutch: Clopidogrel: Evaluatie van de inzet en de nadere voorwaarden]. Amstelveen: College voor Zorgverzekeringen; 2003.

16. Fox DM, Oxman AD, eds. Informing judgment: Case studies of health policy and research in six countries. New York: Milbank Memorial Fund; 2001.

17. Gafni A, Birch S. Incremental cost-effectiveness ratios (ICERs): The silence of the lambda. Soc Sci Med. 2006;62: 2091-2100.

18. Gafni A. Walter SD, Birch S, et al. An opportunity cost approach to sample size calculation in cost-effectiveness analysis. Health Econ. 2008;17:99-107.

19. Green J, Thorogood N. Qualitative methods for health research. London: SAGE; 2004.

20. Ham C, Coulter A. Explicit and implicit rationing: Taking responsibility and avoiding blame for health care choices. $J$ Health Serv Res Policy. 2001;6:163-169.

21. Harris A, Buxton M, O'Brien B, et al. Using economic evidence in reimbursement decisions for health technologies. Expert Rev Pharmacoeconomics Outcomes Res. 2001;1:7-12.

22. Harris J. Cost-effectiveness and resource allocation. Reply to Dr. Cohen. JAMA. 2007;295:2723-2724.

23. Hoedemaekers R, Oortwijn W. Problematic notions in Dutch Health Care package decisions. Health Care Anal. 2003;11:287-94.

24. Kahneman D, Tversky A. Prospect theory: An analysis of decision under risk. Econometrica. 1979;47:263-291.

25. Mauskopf J. Budget impact analysis: Review of the state of the art. Expert Rev Pharmacoeconomics Outcomes Res. 2005;5:6579.

26. Mauskopf J, Sullivan SD, Annemans L, et al. Principles of good practice for budget impact analysis: Report of the ISPOR Task Force on good research practices-budget impact analysis. Value Health. 2007;10:336-347.

27. Mauskopf J. Prevalence-based economic evaluation. Value Health. 1998;1:251-259.
28. McCabe C, Claxton K, Tsuchiya A. Orphan drugs and the NHS: Should we value rarity? BMJ. 2005;331;1016-9.

29. Ministerie van Volksgezondheid, Welzijn en.Sport. IVF back in the benefit package. [in Dutch: IVF komt weer in basispakket.] Nieuwsbericht Den Haag; 2006.

30. Neumann PJ. Commentary on the ISPOR Task Force Report on budget impact analyses. Boston: Center for the Evaluation of Value and Risk in Health; 2007.

31. Niezen MGH, De Bont A, Stolk EA, et al. Conditional reimbursement within the Dutch drug policy. Health Policy. 2007;84:39-50.

32. Niezen-van der Zwet MGH, Stolk EA, Eijck A, et al. Evaluation of Schedule 2 as a policy instrument. [in Dutch: Evaluatie van Bijlage 2 als beleidsinstrument]. Rotterdam: Instituut Beleid en Management Gezondheidszorg / Erasmus MC; 2004.

33. Niezen MGH, Stolk EA, Uyl-de Groot CA, et al. Inequalities in oncology care: Economic consequences of high cost drugs. Eur J Cancer. 2007;42:2887-2892.

34. Orlewska E, Mierzejewski P. Proposal of Polish guidelines for conducting financial analysis and their comparison to existing guidance on budget impact in other countries. Value Health. 2004;7:1-10.

35. Sendi P, Gafni A, Birch S. Ethical economics and costeffectiveness analysis: Is it ethical to ignore opportunity costs? Expert Rev Pharmacoeconomics Outcomes Res. 2005;5:661665.

36. Sendi P, Gafni A, Birch S. Opportunity costs and uncertainty in the economic evaluation of health care interventions. Health Econ. 2002;11:23-31.

37. Sendi P, Al MJ, Rutten FF. Portfolio theory and costeffectiveness analysis: A further discussion. Value Health. 2004;7:595-601.

38. Sendi PP, Briggs AH. Affordability and cost-effectiveness: Decision-making on the cost-effectiveness plane. Health Econ. 2001;10:675-680.

39. Stolk EA, Brouwer WB, Busschbach JJ. Rationalising rationing: Economic and other considerations in the debate about funding of Viagra. Health Policy. 2002;59:53-63.

40. Trueman P, Drummond M, Hutton J. Developing guidance for budget impact analysis. Pharmacoeconomics. 2001;19:609621.

41. Ubel PA, DeKay ML, Baron J, et al. Cost-effectiveness analysis in a setting of budget constraints-is it equitable? $N$ Engl J Med. 1996;334:1174-1177.

42. Van Luijn JCF. CFH-rapport 99/05 Clopidogrel (Plavix) Ferrioxidesaccharaat (Venofer) Lactulose Granulaat (Legendal). Amstelveen; CVZ: 1999.

43. Van Oostenbruggen MF, Jansen RB, Mur K, et al. Penny and pound wise: Pharmacoeconomics from a governmental perspective. Pharmacoeconomics. 2005;23:219-226. 